\title{
Emotional outcomes after stroke: factors associated with poor outcome
}

\author{
Martin Dennis, Suzanne O’Rourke, Stephanie Lewis, Michael Sharpe, Charles Warlow
}

\begin{abstract}
Objectives-The impact of stroke on the emotional outcome of patients is large. The aim was to describe the emotional outcomes among a cohort of patients which was of sufficient size to provide a precise estimate of their frequency and help identify those factors which are associated with poor outcomes after an acute stroke.

Methods-372 surviving patients, who had been referred to a hospital and entered into a randomised trial to evaluate a stroke family care worker, were asked to complete questionnaires at a 6 month follow up. These included measures of emotional distress (general health questionnaire 30 item, hospital anxiety and depression scale) and physical functioning (modified Rankin, Barthel index). A regression analysis was used to identify factors which were independently associated with poor outcomes.
\end{abstract} Results-184 (60\%) surviving patients scored more than 4 on the GHQ-30, 55 $(22 \%)$ more than 8 on the HAD anxiety subscale, and $49(20 \%)$ more than 8 on the HAD depression subscale. Patients with severe strokes resulting in physical disability were more likely to be depressed whereas there was a less strong relation between disability and anxiety. Patients with posterior circulation strokes had consistently better emotional outcomes than those with anterior circulation strokes.

Conclusions-These data may help identify those patients at greatest risk of poor emotional outcomes and thus help in planning trials and delivering appropriate interventions.

(F Neurol Neurosurg Psychiatry 2000;68:47-52)

Keywords: stroke; depression; anxiety; emotion; mood; outcome; predictors

Although most studies of stroke outcome have focused on the physical consequences, there is increasing evidence that patients are also prone to emotional problems. Estimates of the frequency of emotional problems have varied depending on the type of stroke patients included, the timing of assessments, and the measurement tools used. ${ }^{1}$ Most studies have focused on depression and not included other aspects of emotional outcome, such as anxiety, although their impact may be considerable. ${ }^{2}{ }^{3}$ Moreover, they included relatively few patients so their estimates of frequency are rather imprecise. In addition many studies have attempted to identify factors which are associated with the development of emotional problems after stroke. Most have focused on the impact of lesion location and size on depression after the work of Robinson et al in Baltimore. ${ }^{4}$ However, the results have been inconsistent because of the few subjects studied and their failure to adjust for potential confounding factors. Knowledge of those factors which are associated with poststroke emotional distress might provide clues to their cause, help identify those who are at greatest risk, refine the design of randomised trials of interventions aimed at their prevention and treatment, and help to target those interventions on those at greatest risk.

We have gathered a large cohort of well characterised patients with acute stroke and followed them up at 6 months to identify their emotional outcome using simple measures. We have also attempted to identify those factors which are associated with poor outcomes.

\section{Patients and methods}

We identified patients with first or recurrent stroke as part of a randomised trial to evaluate the effectiveness of a stroke family care worker. ${ }^{5}$ This trial had broad entry criteria and included $67 \%$ of all patients assessed within 30 days of a stroke at one of two major hospitals serving the population of Edinburgh and its environs over a 2 year period. We included both those admitted to our hospital and those who only attended outpatient clinics. Patients with subarachnoid haemorrhage were not eligible. The main reasons for exclusion were: residence more than 25 miles from the hospital, low probability of surviving more than a few days, and additional non-stroke illness which would dominate patients' care-for example, chronic renal failure or advanced malignancy. Baseline data were collected just before randomisation. Patients were assessed by a stroke physician who elicited a full history, clinical examination, and classified the stroke according to the Oxfordshire Community Stroke Project classification which has been shown to predict the site and size of brain lesion on CT. ${ }^{67}$ We followed up surviving patients at 6 months, usually in their own home, and assessed them using: the modified Rankin scale ${ }^{8}$ (score 0 best, 5 worst), Barthel index (0 worst, 20 best), hospital anxiety and depression scale (HAD) $)^{10}$ ( 0 best, 21 worst), and the general health questionnaire-30 item version $(\mathrm{GHQ})^{11}(0$ best, 30 worst). The authors of these measures of emotional distress suggested cut off points which identify patients in general populations likely to have diagnosable psychological 
Table 1 Associations between baseline factors and emotional outcomes at 6 months poststroke

\begin{tabular}{|c|c|c|c|c|c|c|c|c|c|}
\hline \multirow[b]{2}{*}{ Baseline characteristic } & \multirow[b]{2}{*}{ Value } & \multicolumn{3}{|c|}{$G H Q-30$} & \multicolumn{3}{|c|}{ HAD Anxiety } & \multicolumn{2}{|c|}{ HAD Depression } \\
\hline & & $n$ & Median & $p$ & $n$ & Median & $p$ & Median & $p$ \\
\hline \multirow{2}{*}{ Current smoker } & Yes & 130 & 7 & 夫 & 108 & 6 & $\star$ & 5 & * \\
\hline & No & 179 & 5 & & 143 & 4 & & 3 & \\
\hline \multirow{3}{*}{ Employed at time of stroke } & Yes & 70 & 4.5 & & 59 & 5 & & 3 & $\star$ \\
\hline & No & 238 & 6 & & 191 & 5 & & 4 & \\
\hline & Missing & 1 & 5 & & 1 & 5 & & 5 & \\
\hline \multirow[t]{2}{*}{ Previous stroke } & Yes & 55 & 6 & & 48 & 4 & & 5 & $\star$ \\
\hline & No & 254 & 6 & & 203 & 5 & & 4 & \\
\hline \multirow[t]{2}{*}{ Total anterior circulation stroke ${ }^{6}$} & Yes & 32 & 11.5 & $\star \star$ & 22 & 7 & & 8 & * \\
\hline & No & 277 & 6 & & 229 & 4 & & 4 & \\
\hline \multirow{2}{*}{ Posterior circulation stroke } & Yes & 57 & 4 & $\star$ & 54 & 3 & $\star$ & 3 & $\star$ \\
\hline & No & 252 & 7 & & 197 & 6 & & 4 & \\
\hline \multirow[t]{3}{*}{ Arm power } & Moderate/better & 263 & 5 & $\star \star$ & 218 & 5 & & 4 & $\star$ \\
\hline & Poor & 45 & 11 & & 32 & 6.5 & & 5.5 & \\
\hline & Missing & 1 & 5 & & 1 & 5 & & 5 & \\
\hline \multirow[t]{2}{*}{ Able to walk independently } & Yes & 195 & 5 & $\star$ & 162 & 5 & & 3 & $\star$ \\
\hline & No & 114 & 8 & & 89 & 4 & & 5 & \\
\hline \multirow[t]{3}{*}{ Visual field defect } & Yes & 57 & 8 & $\star$ & 36 & 7 & & 6.5 & $\star \star$ \\
\hline & No & 243 & 5 & & 207 & 4 & & 3 & \\
\hline & Missing & 9 & 7 & & 8 & 10 & & 10.5 & \\
\hline \multirow[t]{3}{*}{ Visuospatial disorder } & Yes & 59 & 9 & $\star$ & 38 & 6 & & 7.5 & $\star \star$ \\
\hline & No & 236 & 5 & & 201 & 4 & & 4 & \\
\hline & Missing & 14 & 7 & & 12 & 6.5 & & 4.5 & \\
\hline \multirow[t]{3}{*}{ Hodkinson mental test score ${ }^{13}$} & $\leqslant 8$ & 46 & 8 & * & 32 & 7 & & 6 & * \\
\hline & $>8$ & 222 & 6 & & 188 & 4.5 & & 4 & \\
\hline & Not assessable & 41 & 6 & & 31 & 5 & & 4 & \\
\hline \multirow[t]{2}{*}{ Urinary incontinence } & Yes & 36 & 7.5 & $\star$ & 23 & 7 & & 7 & * \\
\hline & No & 273 & 6 & & 228 & 4.5 & & 4 & \\
\hline
\end{tabular}

${ }^{\star} \mathrm{p}<0.05 ;{ }^{\star \star} \mathrm{p}<0.001$

There were no statistically significant differences in the GHQ or HAD subscales in patients with and without the following characteristics: male sex $>65$ y, prestroke modified Rankin $>2$, living alone before stroke, partial anterior circulation stroke, lacunar stroke, left hemispheric stroke, Glasgow coma scale verbal score abnormal, visible infarction on CT, haemorrhage on CT.

illness - for example, depression. We have used these but have supplemented them with other cut off points which we have previously shown to be more appropriate in stroke survivors. ${ }^{12}$

ANALYSES

We first described the distribution of scores on the various measures using non-parametric statistics. Secondly, we compared the scores on these measures for patients who differed in terms of certain characteristics using Wilcoxon two sample tests. Thirdly, we examined the strength of association between the various measures of physical and emotional states at 6 months using Spearman's ranked correlation coefficients. Lastly, we performed regression analyses to identify the independent contribution of each variable which we had identified in our univariate analysis.

\section{LITERATURE REVIEW}

To put our results in context we identified similar studies using a MEDLINE search (using OVID) 1966-98 (search strategy available from authors) and reviewed the reference lists of relevant papers. We included prospective cohort studies of stroke patients which had collected a range of clinical and demographic variables at baseline and followed up more than 150 patients for at least 3 months, to determine their emotional state.

\section{Results}

We enrolled 417 patients in the study. To determine how representative they were of those referred to our hospital we compared their baseline characteristics with those patients referred to our hospital during the study period but who were not enrolled. The main reason for exclusion was on the basis of geography and the likelihood of early death which explains most of the differences seen. Patients included were younger (mean 64.6 years $v 67.8$ years; $\mathrm{p}=0.006$ ) and more likely to live alone $(32 \%$ v $21 \% ; \mathrm{p}=0.003)$ but were otherwise similar.

Of the 417 enrolled, 41 (10\%) died before follow up, one was found to have a brain tumour, two refused follow up, and one had migrated abroad. Thus 372 stroke patients were followed up ( $99 \%$ of surviving patients). Of these, 370 (99\%) completed the modified Rankin and Barthel index, 309 (83\%) the GHQ, and $251(67 \%)$ the HAD subscales. The main reasons for non-completion were cognitive and communication problems and turning over two pages at once when completing self report questionnaires. The lower rate of completion for the HAD was probably because this was left with patients at the time of the interview to be sent back to us by post rather than being completed in the presence of our research psychologist. Non-responders to the HAD were more likely to have had a prestroke modified Rankin of $>2$, to have a Hodkinson abbreviated mental test score at baseline of $<8$, to have a visual field defect, and an anterior circulation stroke (total anterior circulation stroke (TACS), posterior circulation stroke

Table 2 Associations between the outcome measures

\begin{tabular}{lllll}
\hline HAD-Anx & HAD-Dep & Rankin & Barthel & \\
\hline 0.6 & 0.7 & 0.5 & -0.4 & GHQ \\
& 0.7 & 0.3 & -0.2 & HAD-Anx \\
& & 0.5 & -0.4 & HAD-Dep \\
& & & -0.8 & Rankin
\end{tabular}

The above are Spearman's rank correlation coefficients between the various measures. The negative correlations simply reflect the fact that certain scores are higher in patients with worse outcomes and vice versa. $p$ Values for all of these values are $<0.01$. 
Table 3 Models resulting from forward regression analyses to predict the patients'outcomes on our measures of emotional function. We included modified Rankin at 6 months as an independent variable to optimally adjust for physical outcome

\begin{tabular}{|c|c|c|}
\hline Variable & Model $R^{2}$ & $\begin{array}{l}p \text { Value on } \\
\text { entry to model }\end{array}$ \\
\hline \multicolumn{3}{|l|}{ GHQ-30 } \\
\hline \multicolumn{3}{|l|}{ Baseline data only: } \\
\hline Total anterior circulation stroke (TACS) & 0.06 & $<0.01$ \\
\hline Poor arm power & 0.09 & $<0.01$ \\
\hline Age $>65 y$ & 0.10 & 0.04 \\
\hline \multicolumn{3}{|l|}{ Six month functional status inserted first: } \\
\hline Modified Rankin $>2$ at 6 months & 0.18 & $<0.01$ \\
\hline Prior disability & 0.21 & $<0.01$ \\
\hline Age $>65 y$ & 0.23 & 0.01 \\
\hline Total anterior circulation stroke (TACS) & 0.24 & 0.04 \\
\hline \multicolumn{3}{|l|}{ HAD Anxiety } \\
\hline \multicolumn{3}{|l|}{ Baseline data only: } \\
\hline Anterior circulation stroke (TACS, PACS or LACS $^{6}$ ) & 0.03 & $<0.01$ \\
\hline Visual field defect & 0.05 & $<0.05$ \\
\hline \multicolumn{3}{|l|}{ Six month functional status inserted first: } \\
\hline Modified Rankin $>2$ at 6 months & 0.07 & $<0.01$ \\
\hline Anterior circulation stroke & 0.09 & 0.02 \\
\hline Unable to walk & 0.11 & 0.05 \\
\hline \multicolumn{3}{|l|}{ HAD Depression } \\
\hline \multicolumn{3}{|l|}{ Baseline data only: } \\
\hline Visual field defect & 0.06 & $<0.01$ \\
\hline Prior stroke & 0.10 & $<0.01$ \\
\hline Anterior circulation stroke & 0.13 & $<0.01$ \\
\hline Prior disability & 0.15 & $<0.03$ \\
\hline \multicolumn{3}{|l|}{ Six month functional status inserted first: } \\
\hline Modified Rankin $>2$ at 6 months & 0.20 & $<0.01$ \\
\hline Visual field defect & 0.22 & $<0.01$ \\
\hline Prior stroke & 0.25 & $<0.01$ \\
\hline Anterior circulation stroke & 0.27 & 0.01 \\
\hline
\end{tabular}

$\mathrm{R}^{2}=$ Cumulative proportion of variance explained by factor.

(POCS), or lacunar circulation stroke (LACS)).

The patients had a median modified Rankin score of 2 (interquartile range (IQR) 2-3) and a median Barthel index of 19 (IQR 16-20) at follow up. Their median score on the GHQ was 6 (IQR 2-12) with $184(60 \%)$ having a score greater than 4 (the number exceeding other cut off points are given in table 4). Their median score on the HAD depression subscale was four (IQR 2-7) with 78 (31\%) scoring more than 6 (the number exceeding other cut off points are also given in table 4 . Their median score on the HAD anxiety subscale was 5 (IQR $2-8)$, with $96(38 \%)$ having scores greater than
$6,55(22 \%)$ greater than 8 , and $39(16 \%)$ greater than 10 .

UNIVARIATE ANALYSES

There were no statistically significant differences in mood between patients in the treatment and control groups. ${ }^{5}$ The median scores on each of our measures of emotional outcome for patients with and without certain characteristics at baseline are shown in table 1. This univariate analysis shows the baseline features which are associated (at statistical significance levels of $\mathrm{p}<0.05$ and $\mathrm{p}<0.001$ ) with different emotional outcomes. Baseline characteristics which indicated a more severe stroke were generally associated with worse scores on the GHQ and the HAD depression score at 6 months (table 1). However, only current smoking, and an anterior circulation stroke (compared with posterior circulation strokes) ${ }^{6}$ were significantly associated with a worse score on the HAD anxiety subscale. Those who were smoking at the time of their stroke had consistently worse emotional outcomes than non-smokers. One of the most consistent findings was the better emotional outcomes among patients with posterior circulation strokes compared with those in the anterior circulation. In this study there were only small differences in measures of emotional outcome between patients with stroke lesions in their right and left hemisphere (determined clinically rather than radiologically) and these were not significant $(\mathrm{p}>0.05)$.

CORRELATIONS

The strengths of the correlations between the various outcome measures are shown in table 2. Not surprisingly the correlations between modified Rankin and Barthel index were good, as were those between GHQ and HAD subscales. There were significant although weaker correlations between the physical and emotional measures. The weakest correlations

Table 4 Large studies $(n>150)$ which have reported the frequency of depression * after stroke

\begin{tabular}{|c|c|c|c|c|c|c|c|}
\hline Study & Setting & Type of stroke & $\begin{array}{l}\text { Number at } \\
\text { baseline }\end{array}$ & Measure(s) used & $\begin{array}{l}\text { Cut off(s) } \\
\text { used }\end{array}$ & $\begin{array}{l}\text { Timing of } \\
\text { assessment }(s)\end{array}$ & $\begin{array}{l}\% \text { depressed of } \\
\text { (n) followed up }\end{array}$ \\
\hline Wade et $a l^{15}$ & Community & All & 976 & Wakefield & $>14$ & $\begin{array}{l}6 \text { months } \\
1 \mathrm{y}\end{array}$ & $\begin{array}{l}32 \%(377) \\
31 \%(348)\end{array}$ \\
\hline Ebrahim et al ${ }^{16}$ & Hospital & All & 463 & GHQ-28 ${ }^{@}$ & $>11$ & 6 months & $23 \%(149)$ \\
\hline Andersen et al ${ }^{17}$ & Hospital & $\begin{array}{l}\text { All } \\
\text { First }\end{array}$ & $\begin{array}{l}285 \\
211\end{array}$ & HDRS & $>13$ & during year & $\begin{array}{l}41 \%(230) \\
33 \%(177)\end{array}$ \\
\hline Burvill et al ${ }^{18}$ & Community & First & 370 & PAS - DSMIII & $\mathrm{n} / \mathrm{a}$ & 4 months & $28 \%(191)$ \\
\hline Herrmann et al $^{19}$ & Hospital & Hemispheric & 450 & $\begin{array}{l}\text { Zung } \\
\text { MADRS }\end{array}$ & $\begin{array}{l}>49 \\
>6\end{array}$ & $\begin{array}{l}3 \text { months } \\
1 \mathrm{y} \\
3 \text { months } \\
1 \mathrm{y}\end{array}$ & $\begin{array}{l}22 \%(150) \\
21 \%(133) \\
27 \%(150) \\
22 \%(133)\end{array}$ \\
\hline Kotila et $a l^{20}$ & Community & First & 594 & BDI & $>9$ & $\begin{array}{l}3 \text { months } \\
1 \mathrm{y}\end{array}$ & $\begin{array}{l}47 \%(321) \\
47 \%(311)\end{array}$ \\
\hline Pohjasvaara $e^{a} a l^{21}$ & Hospital & All & 486 & $\begin{array}{l}\text { PSE - DSMIIIR } \\
\text { BDI }\end{array}$ & $\begin{array}{l}\mathrm{n} / \mathrm{a} \\
>9 \\
>13\end{array}$ & 3-4 months & $\begin{array}{l}40 . \%(277) \\
38 \%(260) \\
18 \%(260)\end{array}$ \\
\hline Current study & Hospital & All & 417 & $\begin{array}{l}\text { GHQ-30 } \\
\text { HAD dep }\end{array}$ & $\begin{array}{l}>4 \\
>8 \\
>6 \\
>8 \\
>10\end{array}$ & 6 months & $\begin{array}{l}60 \%(309) \\
38 \%(309) \\
31 \%(251) \\
20 \%(251) \\
12 \%(251)\end{array}$ \\
\hline
\end{tabular}

Wakefield=Wakefield depression inventory; BDI=Beck depression inventory; HDRS=Hamilton depression rating scale; GHQ-28/ $30=$ general health questionnaire-28/30 item score; CES-D=Center for Epidemiological Studies-depression scale; Zung=Zung self rating depression scale; MADRS=Montgomery Asberg depression rating scale; HAD dep=hospital anxiety and depression scale-depression subscale; PSE=present state examination; PAS=psychiatric assessment schedule.

*The GHQ does not specifically relate to depression but rather to likelihood of a diagnosable psychiatric disorder. 
Table 5 Factors associated with depression after stroke in this and previous similar studies

\begin{tabular}{|c|c|c|c|c|c|c|c|c|}
\hline Factor & $\begin{array}{l}\text { Wade } \\
\text { et }^{1 l^{15}}\end{array}$ & $\begin{array}{l}\text { Ebrahim } \\
\text { et } a^{16}\end{array}$ & $\begin{array}{l}\text { Andersen } \\
\text { et } \text { al }^{17}\end{array}$ & $\begin{array}{l}\text { Burvill } \\
\text { et al }\end{array}$ & $\begin{array}{l}\text { Herrman } \\
\text { et al }\end{array}$ & $\begin{array}{l}\text { Kotila } \\
\text { et } \text { al }^{2}\end{array}$ & $\begin{array}{l}\text { Pohjasvaara } \\
\text { et al }\end{array}$ & $\begin{array}{l}\text { Current } \\
\text { study }\end{array}$ \\
\hline Increasing age & ++ & - & - & - & ++ & ++ & - & - \\
\hline Female sex & ++ & - & ++ & - & + & + & - & - \\
\hline Living alone & 0 & - & + & 0 & 0 & - & 0 & - \\
\hline Prior stroke & 0 & - & + & 0 & 0 & 0 & - & ++ \\
\hline Prior disability & 0 & 0 & 0 & 0 & 0 & - & 0 & - \\
\hline Comorbidity & 0 & 0 & - & - & 0 & - & 0 & 0 \\
\hline Prior depression & 0 & 0 & + & 0 & ++ & 0 & ++ & 0 \\
\hline Prior social distress & 0 & 0 & + & 0 & 0 & 0 & 0 & 0 \\
\hline Not working before & 0 & 0 & 0 & 0 & 0 & 0 & 0 & + \\
\hline Low social class & 0 & 0 & + & - & 0 & 0 & 0 & 0 \\
\hline Prior smoker & 0 & 0 & 0 & 0 & 0 & 0 & 0 & + \\
\hline Stroke severity & 0 & + & 0 & 0 & ++ & ++ & ++ & ++ \\
\hline Side & - & - & - & 0 & - & - & - & - \\
\hline Lesion volume & 0 & 0 & - & 0 & ++ & 0 & 0 & 0 \\
\hline Anterior circulation & 0 & 0 & - & 0 & 0 & 0 & - & ++ \\
\hline Cognitive impairment & + & 0 & ++ & - & ++ & 0 & - & + \\
\hline Poor functional status & + & + & - & + & ++ & 0 & ++ & ++ \\
\hline Low social activity & ++ & 0 & ++ & + & 0 & 0 & 0 & 0 \\
\hline $\begin{array}{l}\text { Proportion of variance } \\
\text { explained by best model }\end{array}$ & $60 \%$ & & $42 \%$ & & $18 \%$ & & & $27 \%$ \\
\hline
\end{tabular}

Note: $++=$ significant $(\mathrm{p}<0.05)$ in multivariate model; $+=$ significant $(\mathrm{p}<0.05)$ in univariate analysis; $0=$ not examined $/ \mathrm{reported}$; $-=$ not significant in either univariate or multivariate model

were between the HAD anxiety scale and those reflecting physical abilities.

\section{Regression analysis}

Univariate analyses had shown that several characteristics measured at baseline were closely related to the patients' emotional outcomes measured using both the GHQ and HAD. However, many of these factors are likely to reflect a similar underlying characteristicfor example, the patients' age and severity of stroke. We therefore performed a forward regression analysis to identify those factors which were independently associated with each measure of emotional outcome and which explained the greatest proportion of the variance in outcome. The following possible explanatory variables were used: age $(<65$ years $v \geqslant 65$ years), sex, prestroke modified Rankin score (0-2 $v 3-5)$, ability to walk independently, arm power, Glasgow coma scale verbal score, urinary incontinence, visuospatial disorder, and presence or absence of visual field defect, TACS, POCS, living alone, any previous stroke, Hodkinson mental test score ${ }^{13}$ and visible infarction on CT. A forward selection procedure was used. This process identified several baseline factors which were independent predictors of patients' emotional outcome at 6 months (table 3). Some of these factors also predicted patients' physical outcome. Although these might be useful in predicting at baseline which patients would develop later emotional problems we also wanted to understand the possible determinants of emotional outcome. We therefore repeated the modelling process inserting the patients' actual 6 month functional outcome, measured using the modified Rankin scale first. These models explained a greater proportion of the variance and are also shown in table 3 .

\section{Discussion}

In this study we have described the emotional outcomes of patients 6 months after having had a stroke. Several methodological points have to be considered when interpreting our data. Firstly, the patients were identified as part of a randomised trial and therefore may not be typical of stroke patients in general. However, $67 \%$ of all referred patients were entered into this trial and the main reasons for exclusion were that they lived outside our catchment area or were expected to die soon after the stroke. These factors are unlikely to have biased our results but other potential sources of bias must not be overlooked, such as the original reason for referral to our hospital, and refusal or incomplete responses to questionnaires. Secondly, we were not able to identify a suitable control group so we cannot comment on whether our patients had different outcomes to those with other diseases, nor indeed from healthy people in the general population. Thirdly, we did not use a structured psychiatric interview in all patients although we have previously shown that the GHQ and HAD are reasonably valid indicators of psychiatric morbidity. ${ }^{12}$ Fourthly, we did not perform either prestroke or early poststroke assessments of patients' mood and cannot therefore comment on the importance of earlier psychiatric distress as a predictor of later problems. Nor did we perform detailed analysis of brain imaging in the main cohort to establish whether psychiatric morbidity was associated with lesion location although we have reported our findings on a small subgroup previously. ${ }^{14}$ Finally, we examined the association between a large number of baseline and outcome variables. It is therefore possible that we obtained some spurious results due to multiple testing.

It is useful to set this study in the context of similar studies to identify common findings as this might help distinguish real associations and those which are more likely to have occurred by chance. Many studies of poststroke emotional problems, principally depression, have focused only on lesion location as a potential predictor, have had a short follow up, and have included rather few patients and have therefore provided imprecise estimates of the frequency of depression and have not been able to reliably identify those factors which predict or are associated with emotional outcome. We 
have limited our discussion to larger prospective studies as they are those most likely to provide precise estimates of the frequency of emotional problems and robust evidence on prognostic factors. ${ }^{15-21}$

\section{FREQUENCY OF DEPRESSION}

Table 4 summarises the other studies which have reported the frequency of emotional problems, principally depression, in large cohorts of stroke survivors. These studies attempted to assess all survivors at various intervals poststroke. The frequencies of depression varied considerably $\left(22 \%{ }^{19}\right.$ to $\left.47 \%{ }^{20}\right)$ but were broadly similar to those in our study. It is unclear how much of this variation is due to differences in patient selection, methods, and timing of measurement and treatment. Some studies were community based ${ }^{151820}$ and thus might have been expected to include a greater proportion of less severe strokes than hospital based studies. ${ }^{16171921}$ The proportion of survivors who completed the measurement tools also varied considerably. Most often communication and cognitive impairments accounted for the incomplete data. However, in some studies significant numbers (up to $43 \%{ }^{21}$ ) of patients were not followed up for various reasons, which might have introduced further selection bias if the reasons for refusal or loss to follow up were related to their emotional state. Andersen et $\mathrm{l}^{17}$ reported that $47 \%$ of those who were unable to complete the formal assessments of depression were in fact probably depressed.

These studies used various self report mood scales; only two used a diagnostic psychiatric interview. ${ }^{18}{ }^{21}$ Most of the scales relate to depression although the GHQ aims to identify patients who are likely to have any diagnosable psychiatric condition. Although most of these scales have been validated in stroke patients there have been very few studies which have directly related one measure to another, so making comparisons between the frequency of mood disorder in these studies difficult. However, from our own study and that of Herrmann et $a l^{19}$ it is clear that the measurement scale used and the cut off points chosen can have a major impact on the frequency. The duration of follow up varied between 3 and 12 months, which may influence outcome as emotional state often varies over the first year.

FREQUENCY OF ANXIETY

None of these large studies included a measure of anxiety despite this being identified as an important cause of distress in smaller community based studies. $^{2}{ }^{3}$ The group from Maryland ${ }^{22-24}$ have shown that generalised anxiety disorder (GAD) is common in the acute phase $(26 \%)$, especially in patients with previous psychiatric problems, and often persists but new cases occur during the first 2 years of follow up. Astrom et $a l^{25}$ found that, in a population based cohort of stroke patients and patients with transient ischaemic attacks $(n=80), 20(28 \%)$ had GAD, in the acute stage of which 11 had major depression. At three months $22(31 \%)$ of 70 assessable patients had GAD, 15 with major depression and at 1 year
$16(24 \%)$ of 66 had GAD, 9 with major depression). Despite the difficulties in comparing studies it can be concluded that at least that emotional problems, depression and anxiety, are common in the year following a stroke.

PREDICTIVE FACTORS

The factors which have been found to be associated with depression after stroke in this and previous studies are summarised in table 5 . Some focused on baseline factors whereas others studied how emotional outcomes related to other types of outcome-for example, physical and social. Most of the studies, in common with our own, have shown that patients with more severe strokes (measured at baseline), and/or more physical and/or social restriction at follow up have higher scores on depression scales. Older age and female sex have been variably associated with depression but these factors generally explain only a small proportion of the variance in mood score. Prior stroke, prestroke dependency, and living alone seemed to be related to worse depression scores but were often of borderline statistical significance and generally dropped out of multivariate analyses. None of these large studies found convincing evidence that the side of the stroke lesion had a major impact on the occurrence of depression, which is consistent with a recent systematic review of the literature. ${ }^{26} \mathrm{We}$ found that patients with posterior circulation strokes had a consistently better emotional outcome, even having allowed for residual disability but another study failed to show this relation. ${ }^{21}$ However, in a group of 79 patients Starkstein et al found lower rates of depression among those with posterior circulation strokes compared with those in the middle cerebral artery territory. ${ }^{27}$

The factors and multivariate models identified in these studies failed to explain much of the variance in mood score. In some instances where models seem to predict a larger part of the variance in depression this was in part due to inclusion of factors within the model which directly reflected the mood of the patients (for example, brief cognitive scale ${ }^{17}$ ). Other factors which were measured in only the minority of studies, such as prestroke depression and cognitive function presumably explain some of the remaining variance. Unfortunately we did not measure prestroke depression in this study and although there was a strong trend for patients with poor cognitive function to have more depressive symptoms this did not reach conventional levels of statistical significance in this cohort. Future studies might examine the relation that these and other factors such as emotional support, treatment, and socioeconomic variables have on depression.

Neither we nor Astrom ${ }^{25}$ identified that sex or age predicted those who were likely to develop GAD although the group from Maryland have shown that GAD is commoner in young patients and women. We found quite a strong correlation between scores on the two subscales of the HAD which fits with the findings of $A_{\text {strom }}{ }^{25}$ and the group from Maryland $^{22-24}$ that GAD and depression often 
coexist. Astrom ${ }^{25}$ showed that those with greater disability and fewer social contacts had a greater likelihood of GAD but neither we, nor the Maryland group confirmed this. There is little evidence that GAD is associated with specific lesion locations.

The nature of the associations between emotional outcome and the predictive factors identified are unclear. Does poststroke disability cause depressed mood? Might depressed mood cause poor functional outcomes? Does the severity of the brain lesion account for both the physical and emotional consequences? It is likely that the answers to all three questions is "yes" but the relative importance of each will remain uncertain until large randomised trials have shown whether altering predominantly one aspect of outcome-for example, emotional (with, say, antidepressant drugs) impacts on the physical outcomes. The difficulty in determining whether a relation is likely to be causal and in which direction is illustrated by our rather unexpected finding that cigarette smokers had consistently worse emotional outcomes. It seems unlikely that this is causal and, if it is not a statistical quirk, probably reflects patients' pre-existing emotional state or personality as it was not related to significantly worse physical outcomes.

Although symptoms of depression and anxiety often coexist in stroke patients, we have shown that the factors associated with depression do not so strongly predict the level of anxiety. Because anxiety accounts for much of the emotional distress of patients it would seem sensible to employ outcome measures which are sensitive to anxiety as well as depression in randomised trials aimed at testing preventive and treatment strategies. This study, along with others, has identified some of the factors associated with poor emotional outcomes. This is just the first step towards developing predictive tools which might be helpful in targeting patients for preventative interventions.

This research was supported by grants from the Chief Scientist Office (Scotland) and Chest Heart and Stroke Scotland. The Medical Research Council (UK) funds SL who performed the data analysis.

1 House A. Mood disorders after stroke: a review of the evidence. International fournal of Geriatric Psychiatry 1987;2:211-21.
2 House A, Dennis M, Mogridge L, et al. Mood disorders in the year after a first stroke. Brf Psychiatry 1991;158:83-92. 3 Burvill PW, Johnson GA, Jamrozick KD, et al. Anxiety disorders after stroke: results from the Perth community stroke project. Br F Psychiatry 1995;166:320-7.

4 Robinson RG, Kubos KL, Starr LB, et al. Mood disorders in stroke patients: the importance of lesion location. Brain 1984;107:81-93.

5 Dennis M, O'Rourke S, Slattery J, et al. Evaluation of a stroke family care worker: results of a randomised controlstroke family care worker: results

6 Bamford J, Sandercock P, Dennis M, et al. Classification and natural history of clinically identifiable subtypes of cerebral infarction. Lancet 1991;337:1521-6.

7 Mead GE, Lewis SC, Wardlaw JM, et al. How well does the Oxfordshire community stroke project classification predict the site and size of the infarct on brain imaging? $\mathcal{F} \mathrm{Neu}$ rol Neurosurg Psychiatry 1999 (in press).

8 Bamford J, Sandercock P, Warlow C, et al. Inter observer agreement for the assessment of handicap in stroke patients. Stroke 1989;20:828.

9 Mahoney F, Barthel D. Functional evaluation: the Barthel index. Maryland State Medical fournal 1965;14:61-5.

10 Zigmond AS, Snaith RP The hospital anxiety and depression scale. Acta Psychiatr Scand 1983;67:361-70.

11 Goldberg D. The detection of psychiatric illness by questionnaire. Oxford: Oxford University Press, 1972.

12 O'Rourke S, MacHale S, Signorini D, et al. Detecting psychiatric morbidity after stroke. Comparison of the GHQ and the HAD scale. Stroke 1998;29:980-5.

13 Hodkinson HM. Evaluation of a mental test score for assessment of mental impairment in the elderly. Age Ageing 1972;1:233-8.

14 MacHale SM, O'Rourke SJ, Wardlaw JM, et al. Depression and its relation to lesion location after stroke. $\mathcal{F}$ Neurol Neurosurg Psychiatry 1998;64:371-4.

15 Wade DT, Legh-Smith J, Hewer RA. Depressed mood after stroke: a community study of its frequency. Br f Psychiatry 1987;151:200-5.

16 Ebrahim S, Barer D, Nouri F. Affective illness after stroke. Brf Psychiatry 1987;151:52-6.

17 Andersen G, Vestergaard K, Ingemann-Nielsen M, et al. Risk factors for post-stroke depression. Acta Psychiatr Scand 1995;92:193-8.

18 Burvill P, Johnson G, Jamrozik, et al. Risk factors for post-stroke depression. Int $\mathcal{F}$ Geriatr Psychiatry 1997;12: $219-26$.

19 Herrman N, Black SE, Lawrence J, et al. The Sunnybrook stroke study. A prospective study of depressive symptoms and functional outcome. Stroke 1998;29:618-24.

20 Kotila M, Numminen H, Waltimo O, et al. Depression after stroke. Results of the FINNSTROKE study. Stroke 1998;29:368-72.

21 Pohjasvaara T, Leppavuori A, Siira I, et al. Frequency and clinical determinants of post-stroke depression. Stroke 1998;29:2311-17.

22 Castillo CS, Starkstein SE, Federoff JP, et al. Generalized anxiety disorder after stroke. $\mathcal{F}$ Nerv Ment Dis 1993;181: $100-6$.

23 Castillo, Schulz SK, Robinson RG. Clinical correlates of early-onset and late-onset post stroke generalized anxiety. Am F Psychiatry 1995;152:1174-9.

24 Schultz SK, Castillo CS, Kosier JT, et al. Generalized anxiety and depression. Assessment over 2 years after stroke. Am f Psychiatry 1997;5:229-37.

25 Astrom M. Generalized anxiety disorder in stroke patients. A 3 year longitudinal study. Stroke 1996;27:270-5.

26 Singh A, Herrmann N, Black SE. The importance of lesion location in poststroke depression: a critical review. Can $\mathcal{F}$ Psychiatry 1998;43:921-7.

27 Starkstein SF, Robinson RG, Berthier ML, et al. Depressive disorders following posterior circulation as compared with middle cerebral artery infarcts. Brain 1988;111:175-87. 